\title{
AN INTELLIGENT GAS LEAKAGE DETECTOR WITH SMART ALERT AND PREDICTION USING IoT
}

\author{
Gargi N R ${ }^{1}$, Ann Merlin Binu ${ }^{2}$, Ashiga Suresh ${ }^{3}$,Devika Vijay ${ }^{4}$, Jinu P Sainudeeen ${ }^{5}$ \\ ${ }^{1}$ MLMCE, India, nrgargi770@ gmail.com \\ ${ }^{2}$ MLMCE, India, ann.merlin23@gmail.com \\ ${ }^{3}$ MLMCE, India, ashigasuresh@gmail.com \\ ${ }^{4}$ MLMCE, India, devikavijay61@ @mail.com \\ ${ }^{5} \mathrm{MLMCE}$, India, jinups@gmail.com
}

\begin{abstract}
The internet of things to uniquely identified objects and their virtual representations in an Internet-like structure. In this project, the main aim is to detect gas line leakage in under pipeline through internet connectivity and monitoring it daily In the proposed system, the robot keeps moving along the metal pipe it keeps monitoring for any gas leakage, on detection it uses an interface GPS sensor to transmit the location of the leakage detected we have a fully automated insect-like a robot that moves with the gas pipe and detects gas leakages instantly at a low budget. This kit is a demo project that how is leakage is been detecting. We can also use this in industrial applications for detecting pipeline leakages with large size kit. The IoT plays a major role in this because we are going see the location in cloud storage through the internet. And also the values of temperature of the atmosphere present inside the pipeline. This proposed paper is aimed at developing that constantly monitors that gas leak with the help of the electronic sensors. This data is made available real-time through real-time feeds over the internet. This data helps in easily locating the root cause of the emergency condition. This paper proposes an implementation of RFID and sensors in the smart security robot navigation system.
\end{abstract}

Key words: Arduino, IoT, MQ-2 sensor

\section{INTRODUCTION}

Pipeline infrastructure is extremely important to help our country function. In fact, there are roughly 2.4 million miles of pipe in this vast transportation system. Last year alone, American's consumed 29 percent of natural gas and 40 percent of oil as part of our total energy consumption. As energy demand is on the rise, more transmission, gathering and distribution lines will need to be constructed or updated. So why are these pipelines so important? Well, they run across multiple state lines to bring fuels and feedstocks to a variety of consumers that include homeowners, businesses, and power plants. Most people do not realize how often they make use of products that contain oil and natural gas. They can be used for heating and cooling purposes, as a form of heat supply for running stoves, ovens, and clothes dryers. They also help run and power machinery. used to make household products we use every day. Even those products consist of or contain oil or gas by-products. And while we strive to create new technology and fuel supplies for automobiles, there are more than 263 million registered passenger vehicles on the road, most of which thrive on gasoline or diesel consumption. Pipelines supply the necessary fuel for these daily activities to function and keep our country moving, both physically and economically. So gas leakages lead to losses as well as are a threat because they can also lead to fire accidents. Prevention of leakage is very important

\section{LITERATURE SURVEY}

As energy demand is on the rise, more transmission, gathering and distribution lines will need to be constructed or updated. So why are these pipelines so important. Gas pipes play very important roles for cities, industries and thus in growing economies. Gas leakage and gas detection is a major problem in our daily lives and gas wastage is a major issue that needs to be countered[1]. Gas is highly inflammable and inflicts life and property, also leads economic losses also. The development of a prototype of an autonomous android based mobile robot for gas leak detection and localization in large industrial facilities[3]. The thought came up with a system that's able to perform scrutiny tasks in industrial facilities while not having to access unsafe areas directly - and while not requiring any human presence. The robot may be used for routine inspections of facilities or for targeted inspections of specific system components. The freelance quality of the system was enforced with varied navigation sensors and therefore the choice of manual intervention via device at any time. The development of innovative monitoring processes that make the most of state-of-the-art measuring and automation technology as well as robotics promises improvement in the reliability, efficiency and cost-effectiveness of inspections[5]. At identical time, it relieves technical personnel of monotonous, long and effortful tasks. Recently, with large-scale use of natural gas and massive constructions of gas pipelines, more and more public concern is focused on pipeline leakage. The leakage caused by holes on gas pipelines generates economic losses to gas companies and causes risks to the environment and sometimes 
accidents[4]. In order to detect and locate pipeline rupture immediately, the leakage detection method plays a key role in the overall integrity management in the pipeline system. One of the most important applications of transient simulation is dynamic leakage detection[7]. A leakage detection model and the solution were proposed based on the three conservation laws in hydromechanics and the state equation, which includes transient simulation model and volume balance model. Dynamic parameters involved in the model such as pressure, flow and temperature can be acquired through SCADA (Supervisory Control and Data Acquisition) system.Natural gas is an odourless one which consists of compounds made of two elements: carbon and hydrogen called hydrocarbons. Sometimes, due to an accident or if the valve is not properly closed, the gas leaks[6]. This system is aimed at detecting the leakage and sounding an alert so that occupants in the building can maintain optimal ventilation and turn off all electrical appliances or evacuate the vicinity until a redress is made. Therefore, a gas detector with audible/visual alarm tends to solve the common identified problems through the design and construction of a low cost, easy to construct gas detection system via gas sensor.Our aim is to reduce the risks in Kitchen using Internet of Things. With the help of an infrared sensor the issue of gas wastage is also monitored. An alarm goes off whenever the sensor doesn't detect any vessel over the burner beyond a particular time period[2]. The hazardous gases like LPG and propane were sensed and displayed and notify each and every second in the LCD display. If these gases exceed the normal level then an alarm is generated immediately and also an alert message (Email) is sent to the authorized person through the INTERNET and used ARM development board. The advantage of this automated detection and alerting system over the manual method is that it offers quick response time and accurate detection of an emergency and in turn leading faster diffusion of the critical situation[1].

\section{GAS LEAKAGE DETECTOR SYSTEM}

In the proposed system, the robot keeps moving along the metal pipe it keeps monitoring for any gas leakage, on detection it uses an interface GPS sensor to transmit the location of the leakage detected we have a fully automated insect-like a robot that moves with the gas pipe and detects gas leakages instantly at a low budget. Figire1 shows the detector.This kit is a demo project that how is leakage is been detecting. We can also use this in industrial applications for detecting pipeline leakages with large size kit. The IoT plays a major role in this because we are going see the location in cloud storage through the internet. And also the values of temperature of the atmosphere present inside the pipeline. Figure 2 shows the top view of the system. This proposed paper is aimed at developing that constantly monitors that gas leak with the help of the electronic sensors. This data is made available real-time through real-time feeds over the internet. This data helps in easily locating the root cause of the emergency condition. This paper proposes an implementation of RFID and sensors in the smart security robot navigation system

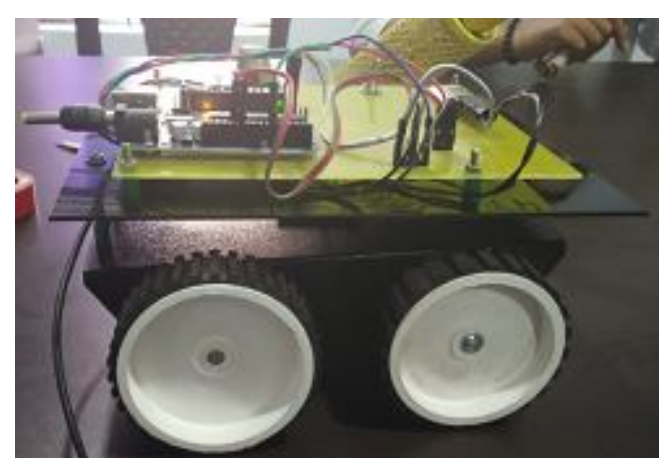

Figure 1: Gas Leakage Detector

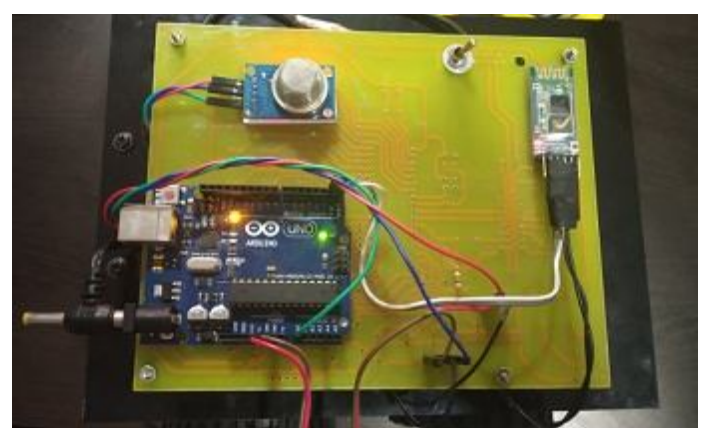

Figure 2: Top view of Gas Leakage Detector System

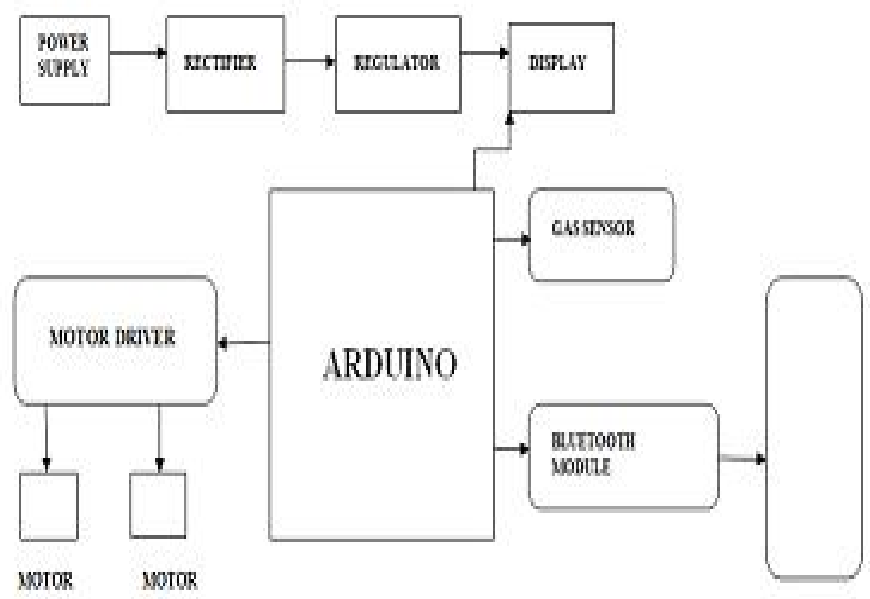

AxDROפมับ:

Figure 3: Architecture 
Here the board used is Arduino. An 8 bit IC Controller and AVR Controller is used. When an analog output is received from MQ-2 sensor. It is given to the Arduino board and checks it in an infinite while loop.If a high value is received, it converts to digital. It varies according to gases and the location is passed to the user or authority through Bluetooth. Two lines called sender and receiver are connected with Arduino board and Bluetooth module for communication. The connection is using IoT. Architecture is shown in the figure 3.

\section{PROPOSED METHODOLOGIES}

\subsection{ARDUINO}

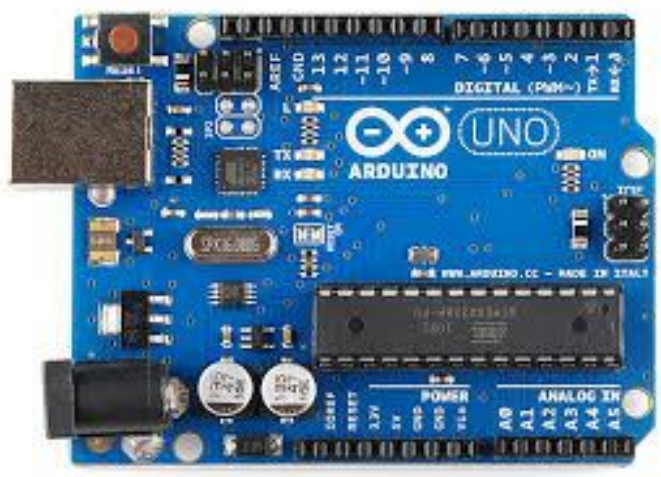

Figure 4: Arduino

Arduino consists of both a physical programmable circuit board (often referred to as a microcontroller) and a piece of software, or IDE (Integrated Development Environment) that runs on your computer, used to write and upload computer code to the physical board. Figure 4 shows the Ardunio.

\subsection{MQ-2 SENSOR}

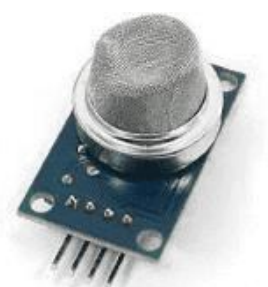

Figure 5:2 MQ-2 SENSOR

The MQ-2 Smoke LPG Butane Hydrogen Gas Sensor Detector Module is useful for gas leakage detection (home and industry). It is suitable for detecting $\mathrm{H} 2$, LPG, CH4, CO, Alcohol, Smoke or Propane. Due to its high sensitivity and fast response time, measurement can be taken as soon as possible. The sensitivity of the sensor can be adjusted by the potentiometer. Figure 5 shows the sensor.

\subsection{BLUETOOTH MODULES}

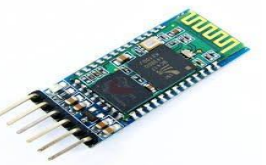

Figure 6: Bluetooth Modules

A BlueTooth module is usually a hardware component that provides. a wireless product to work with the computer; or in some cases, the. bluetooth may be an accessory or peripheral, or a wireless headphone. or other product (such as cell phones can use.).Figure 6 shows Bluetooth modules.

\section{EXPERIMENTAL RESULTS}

The processes that are occurring at the Admin side and Workers side are given below.Results are shown in figure 7, figure 8 and figure 9 .

ADMIN SERVER: By giving the respective user name and password by running IPv4 Address is shown as below:

Login Form

Figure 7::Admin login

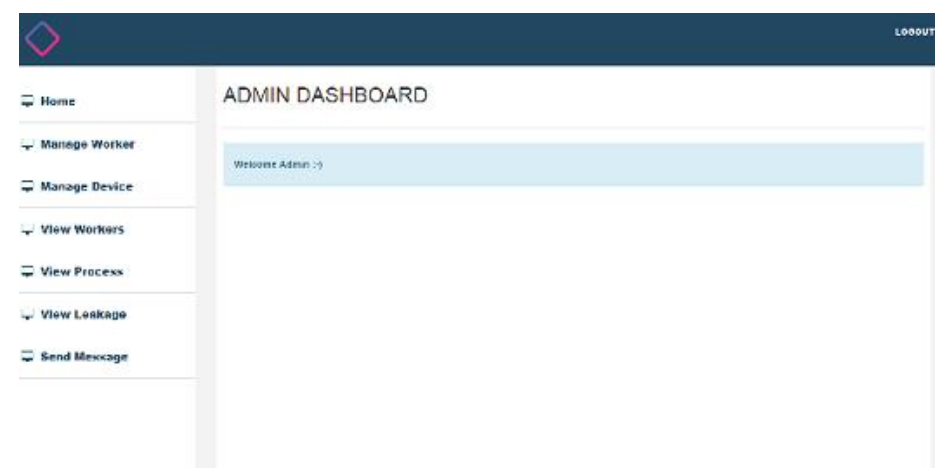

Figure 8:Admin home

WORKER SERVER: Here the worker can operate their system using an Android Mobile. 


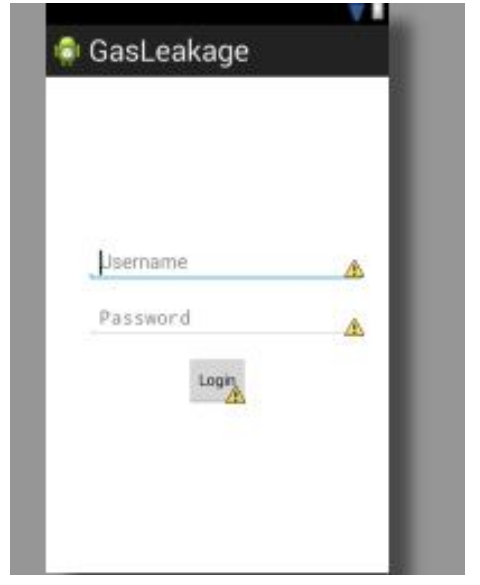

Figure 9: Worker login

\section{CONCLUSION}

The Pipeline infrastructure is extremely important to help our country function. There are roughly 2.4 million miles of pipe in this vast transportation system. Why these pipeline are so important is that they run across multiple state lines tobring fuels and feed stocks to a variety of consumers that include home owners, businesses and power plants. Most people do not realize how often they make use of products that contain oil and natural gas. They can be used for heating and cooling purposes, as a form of heat supply for running stoves, ovens, and clothes dryers. They also help to run and power machinery used to make household products we use every day. Even those products consist of or contain oil or gas by products. Pipelines supply the necessary fuel for these daily activities to function and keep our country moving, both physically and economically. Current existing methods for inspecting and monitoring pipelines use state-of-art technology and sophisticated IT systems to ensure give protect the integrity of the pipe, people, and the environment. Pipeline operators use high-tech inspection devices and extensive preventative methods to discover issues and guard against future failure. Thus we know how important is to be prevent pipelines from gas leakage. Also, like any piece of infrastructure, we must always seek out improvements and upgrade them to meet safety standards just like anything else.

\section{REFERENCES}

[1]AN ANDROID BASED AUTOMATIC GAS DETECTION AND INDICATION ROBOT: $\mathrm{CH}$. MANOHAR RAJU AND N.SUSHMA RANI [2]RESEARCH ON LEAKAGE DETECTION AND ANALYSIS OF LEAKAGEPOINT IN THE GAS PIPELINE
SYSTEM: ZHAO YANG1*,MINGLIANG LIU, MIN SHAO, YINGJIE JI

[3]DANGEROUS GAS DETECTION USING AN INTEGRATED CIRCUIT AND MQ-9: FALOHUN A.S, OKE A.O, ABOLAJI B.M., OLADEJO

[4]IOT BASED GAS PIPE LEAKAGE DETECTOR: PROF. PRADEEP KHATUA, SOURABH SAPKAL, PRASHANT GHODKE

[5]INTERNET OF THINGS (IOT) BASED GAS LEAKAGE MONITORING AND ALERTING SYSTEM WITH MQ-2 SENSOR:ROHAN CHANDRA PANDEY,MANISH VERMA, LUMESH KUMAR SAHU

[6]DEVELOPMENT OF WIRELESS SENSOR NETWORK SYSTEM FOR LPG GAS LEAKAGE DETECTION SYSTEM:T.H.MUJAWAR, V.D.BACHUWAR, M.S. KASBE, A.D. SHALIGRAM AND L.P. DESHMUKH [7]WIRELESS GAS LEAK DETECTION AND LOCALIZATION FABIEN CHRAIM YUSUF BUGRA EROL, KRIS PISTER BERKELEY SENSOR AND ACTUATOR CENTER,UNIVERSITY OF CALIFORNIA, USA 